\title{
Urinary Red Blood Cells: Not Only Glomerular or Nonglomerular
}

\author{
José Antonio Tesser Poloni ${ }^{\mathrm{a}}$ Istifanus Bala Bosan ${ }^{\mathrm{b}}$ Giuseppe Garigali ${ }^{\mathrm{c}}$ \\ Giovanni B. Fogazzic \\ ${ }^{a}$ Central Laboratory of Clinical Analysis, Irmandade da Santa Casa de Misericórdia de Porto Alegre, Porto Alegre, \\ Brazil; ${ }^{b}$ Department of Medicine, Amhadu Bello University Teaching Hospital, Zaria, Nigeria; ${ }^{\mathrm{c}}$ Research Laboratory \\ on Urine, Unità Operativa di Nefrologia e Dialisi, Fondazione IRCCS Ca' Granda, Ospedale Maggiore Policlinico, \\ Milan, Italy
}

\section{Key Words}

Urine sediment $\cdot$ Urinary red blood cells $\cdot$ Hematuria .

Sickle cell disease $\cdot$ Sideropenic anemia $\cdot$ Hemolytic anemia

\begin{abstract}
Two main types of red blood cells, isomorphic and dysmorphic, are found in the urine sediment, indicating nonglomerular and glomerular hematuria, respectively. Occasionally, however, other types of red blood cells such as sickle cells, anisocytes, poikilocytes, elliptocytes and dacryocytes can be seen in the urine sediment of patients with hematuria. This paper describes such cases reported in the literature in which such unusual urinary red blood cells have been found and the experience of the authors on this subject.
\end{abstract}

Copyright $\odot 2011$ S. Karger AG, Basel

\section{Introduction}

Since the publication by Fairley and Birch [1] of their seminal paper on glomerular and nonglomerular hematuria, it is well known that two main types of red blood cells (RBC) can be found in the urine: isomorphic (a marker of nonglomerular bleeding) and dysmorphic $\mathrm{RBC}$ (a marker of glomerular diseases).

\section{KARGER}

Fax +4161306 1234 E-Mail karger@karger.ch www.karger.com

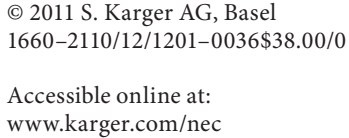

Isomorphic RBC mostly appear as round or biconcave cells with a smooth surface (fig. 1a). The only exception are crenated cells which are characterized by regular spikes (fig. $1 \mathrm{~b}$ and fig. 2a). Dysmorphic RBC, on the other hand, have an irregular shape and contours (fig. 1a) and a wide morphological spectrum, which also includes the so-called acanthocytes [2], which are RBC in the shape of a ring from which one or more blebs of different shapes and sizes protrude (fig. 1a). RBC dysmorphism is thought to be due to distortion of the RBC cytoskeleton that occurs when the cells first pass through the glomerular membrane gaps and then along the renal tubules [3].

However, besides isomorphic and dysmorphic RBC, other types of RBC can occasionally be seen in the urine sediment of patients with hematuria. This paper describes these rare types of urinary $\mathrm{RBC}$ and their clinical associations.

\section{Rare Types of Urinary RBC}

\section{Sickle Cells}

These RBC have the typical morphology of sickle cells observed in peripheral blood of patients with sickle cell disease or trait. Hematuria occurs in $3-4 \%$ of patients 
Fig. 1. a Isomorphic (black arrows), dysmorphic (white arrows) RBC and acanthocytes (arrowheads). b Sickle cells (asterisks) intermingled with isomorphic crenated RBC (phase contrast microscopy, original magnification $\times 400)$.


with sickle cell disease. It is more common in heterozygotes with the sickle cell trait than in homozygotes with sickle cell anemia, as the sickle cell trait is $30-40 \%$ more frequent than sickle cell anemia. Typical patients are young adult black people of Africa and North America, but Afro-Caribbean patients in the West Indies and white patients from different parts of Europe have also been described. Hematuria is typically macroscopic, recurrent and asymptomatic or associated with pain due to passage of clots through the ureters. Microscopic hematuria is less common and sometimes found between two episodes of gross hematuria.

So far, these RBC have been described in the urinary sediment of 9 patients with sickle cell disease or trait with either gross or microscopic hematuria [4-10]. However, it is only in two of these cases that the potential diagnostic role of these cells was considered.

In 1982, Savige et al. [9] described a 33-year-old Greek woman who presented with a 4-week history of gross hematuria and mild left loin pain without other symptoms. Phase-contrast microscopy of the urine sediment $(\mathrm{pH}$ 5.0 , specific gravity 1.020 ) showed $7.5 \%$ dysmorphic RBC, with occasional RBC casts, and $92.5 \%$ isomorphic RBC, some of which showed sickling. This last finding initiated the investigation that led to the diagnosis of sickle cell trait, which before then was unknown. Urine culture yielded Ureaplasma urealyticum, which was treated with doxycycline for 10 days with clearing of gross hematuria. However, microscopic hematuria with sickle cells and $\mathrm{RBC}$ casts persisted after the treatment. A renal biopsy was then proposed to the patient; however, the patient did not consent to this procedure.

In 1996, we described a 16-year-old South African male with recurrent bouts of gross hematuria, with a negative urological workup and a working diagnosis of IgA nephropathy [4]. The urine sediment ( $\mathrm{pH}$ and specific gravity not available), examined during an episode of gross hematuria, showed isomorphic RBC too numerous to count, without other particles suggesting a glomerular disease. Several sickled cells were intermingled with isomorphic RBC (fig. 1b). After this unexpected finding, the electrophoresis of hemoglobin revealed $\mathrm{Hb}$ AS, which is sickle trait, in a patient without a family history of sickle cell disease. The full blood count was normal.

\section{Anisocytes and Poikilocytes}

Anisocytes (RBC with variations in cell size) and poikilocytes (RBC with variation in cell shape; fig. $2 \mathrm{a}$ ), were described in the urine sediment of a 39-year-old Caucasian woman who developed gross hematuria after bilateral pyelostomy done for hydronephrosis from advanced endometriosis [11]. The urine sediment ( $\mathrm{pH}$ 6.7, specific gravity 1.015) showed isomorphic RBC too many to count with several anisocytes and poikilocytes. After a negative search for hemoglobin S, abnormal RBC similar to those found in the urine were found in the peripheral blood smear, a finding which was confirmed by an automated complete blood cell count which showed + anisocytosis, +++ poikilocytosis and +++ microcytosis. Such varia- 



Fig. 2. a Schistocytes and poikilocytes (asterisks) intermingled with crenated and noncrenated isomorphic RBC. b Elliptocytes (asterisks) and isomorphic RBC. c Dacryocytes (asterisks). Phase contrast microscopy (a, c); bright field microscopy (b); original magnification for all images, $\times 400$. tions in size and shape of the peripheral RBC are known to be associated with various types of anemia [12], and it is worth noting that the patient was found to have severe iron deficiency anemia with $9.0 \mathrm{~g} / \mathrm{dl}$ of hemoglobin (normal value 13-17), mean corpuscular volume of $74.5 \mathrm{fl}$ (normal value $80-94$ ), $30 \mu \mathrm{g} / \mathrm{dl}$ of serum iron (normal value 59-158) and very low percentage saturation of transferrin of $6.7 \%$ (normal value $30-50$ ). Thus, the authors concluded that the poikilocytes and anisocytes in the urine were due to the anemia itself [11].

\section{Elliptocytes}

These are elongated RBC with a cigar-like shape (fig. 2b). To our knowledge, these RBC have not been described in urine sediment. We have personally seen elliptocytes in the urine of a 49 -year-old Caucasian woman who received a renal allograft from a cadaveric donor for uremia due to end-stage renal disease of unknown origin in December 2009. In January 2010, the patient, who was under immunosuppressive therapy with prednisolone, tacrolimus and sodium mycophenolate, was hospitalized in Irmandade da Santa Casa de Misericordia Hospital, Porto Alegre, Brazil, for a rapidly progressive rise in serum creatinine up to $7.0 \mathrm{mg} / \mathrm{dl}$. The renal biopsy showed acute cellular rejection, with tubulitis, RBC extravasation in the interstitium and a few RBC within the tubular lumens. The urine examination showed $\mathrm{pH} 8.0$, specific gravity 1.013 , glucose + , albumin +++ , hemoglobin ++ and leukocyte esterase ++ . Nitrites, ketones, bilirubin and urobilinogen were all negative. The urine sediment, by bright field microscopy showed 17-20 RBC per high power field (HPF; $\times 400), 60 \%$ of which were isomorphic while the other $40 \%$ were all elliptocytes. Moreover, there were $>50$ leukocytes per HPF and a moderate amount of waxy, granular and fatty casts. Elliptocytes were also found in subsequent urine sediments, but with fluctuations in number. After the urinary findings, a new examination of the renal biopsy showed that some of the $\mathrm{RBC}$ found within the tubular lumens were actually elliptocytes, intermingled with isomorphic RBC.

The finding of elliptocytes in the urine further supported the investigation of the cause of the anemia the patient was suffering from (hemoglobin $6.3 \mathrm{~g} / \mathrm{dl}, \mathrm{RBC}$ count $2.4 \mathrm{million} / \mu \mathrm{l}$ and $\mathrm{MCV} 86 \mathrm{fl}$ ). Interestingly, the hemogram of the patient showed that elliptocytes $(++)$ were also present in the peripheral blood, which led to the conclusion that the patient had hemolytic anemia, a condition which is often associated with circulating elliptocytes $[13,14]$. 


\section{Dacryocytes}

Dacryocytes are RBC with the shape of 'tear drops' (fig. 2c). To our knowledge, these RBC have also never been described in the urine sediment. We recently saw them in our laboratory in Milano in the urine of a 34-yearold Caucasian woman who had been suffering from lupus nephritis since 2007 (at that time, renal biopsy showed a very active proliferative diffuse glomerulonephritis). On January 20, 2011, the patient, who was under treatment with oral methylprednisolone $32 \mathrm{mg} /$ day, was hospitalized in a rheumatological unit for neurologic symptoms (severe weakness of lower limbs, aphasia and neurologic bladder) and a urinary flare-up of the renal disease, associated with reduced serum C3 level (41 mg/dl; normal value 75-140), positive ANA (1:640, speckled pattern), positive anti ds-DNA (+++) and positive antibodies to extractable nuclear antigens (anti-Sm and anti-RNP). Serum creatinine was $0.6 \mathrm{mg} / \mathrm{dl}$ (eGFR by MDRD equation: $142 \mathrm{ml} / \mathrm{min}$ ) and proteinuria was $4.6 \mathrm{~g} / 24 \mathrm{~h}$. The urine sediment ( $\mathrm{pH} 6.5$, specific gravity 1.020), collected while the patient had a bladder catheter due to the neurologic bladder, contained: 50-70 RBC/HPF; 10-20 white blood cells/HPF; renal tubular epithelial cells, 1 every 9-10/ HPF; ++++ casts (hyalin, hyalin-granular, granular, waxy, erythrocytic, leukocytic, epithelial and fatty); and $1+$ Candida albicans. RBC were $85 \%$ isomorphic and $15 \%$ dysmorphic. There were 2-3 dacryocytes/HPF intermingled with isomorphic RBC, which were also seen in a subsequent urinary sample examined 20 days later. After this finding, peripheral smears were examined, which also showed the presence of dacryocytes. The hemogram showed microcytic anemia (hemoglobin $9.8 \mathrm{~g} / \mathrm{dl}$, RBC count 3.97 million/ $\mu \mathrm{l}, \mathrm{MCV} 70.4 \mathrm{fl}$ ) associated with leu-

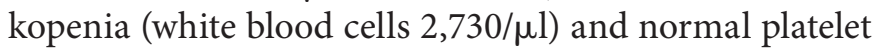
count $(217,000 / \mu l)$. Serum iron, transferrin and ferritin were all in the normal range; direct and indirect Coombs tests were negative.

\section{Discussion}

Hematuria is a frequent manifestation of the diseases of the urinary tract. Among the diseases of nephrological interest, hematuria is particularly frequent in patients with proliferative disorders such as extracapillary glomerulonephritis, IgA nephropathy or acute postinfectious glomerulonephritis [15], which often present with gross hematuria. In such patients, gross hematuria can occasionally cause acute kidney injury associated with acute tubular necrosis, as demonstrated by several studies
[16-18]. In this setting, whether acute kidney injury is due to the tubular obstruction caused by RBC casts, which are a prominent feature in the renal biopsies of such patients, or to tubular toxicity of hemoglobin components of intratubular RBC is not yet clear [18-19]. Similar tubular lesions in the presence of mild glomerular changes have also been observed in patients under warfarin treatment, which was considered the favoring factor for the appearance of gross hematuria and tubular damage [20-21]. Quite importantly, hematuria is also a hallmark of urological diseases - it is often the first sign of a cancer of the urinary excretory system, especially in men 50 years of age or more [22].

In all of these situations, the examination of urine sediment is an important diagnostic tool since it helps in the identification of the causes of hematuria, both through the evaluation of RBC morphology and in the search for particles indicative of an acute tubular damage (e.g. renal tubular epithelial cells, renal tubular epithelial cell casts and granular casts) or a urological disorder (e.g. deep and/or atypical uroepithelial cells).

In the vast majority of patients, $\mathrm{RBC}$ morphology can be categorized as isomorphic (or nonglomerular) or dysmorphic (or glomerular) [1]. Occasionally, however, other types of RBC can be found in urine. Based on the data available in the literature and on our own experience, these can be categorized as sickle cells, poikilocytes, anisocytes, elliptocytes and dacryocytes.

The mechanism(s) for hematuria and unusual type of erythrocyturia in the patients described in this paper vary according to the underlying disease. For sickle cells, the initiating mechanism of the hematuria is the sickling of RBC within the hypoxic, hypertonic and acidotic renal medulla. Sickling of RBC causes stasis within the peritubular capillaries leading to the development of microthrombi and infarction, which increase the permeability of the capillaries and cause interstitial hemorrhage, with spilling of $\mathrm{RBC}$ into the tubular lumina. Intravascular sickling can also lead to papillary necrosis, which is a well-known cause of hematuria in sickle cell trait patients. Moreover, hematuria may also result from hemorrhage secondary to sickling of RBC within the vessels of the pelvis or ureter [4]. Although occasionally bilateral, the hematuria is usually unilateral, the left side being involved four times more commonly than the right. This has been attributed to the increased venous drainage into the left renal vein, which elevates the venous pressure leading to stasis [23].

For the patient with poikilocytes and anisocytes in the urine, hematuria was a complication of the trauma caused 
Table 1. The urinary RBC described in the paper, with their clinical associations and main morphologies

\begin{tabular}{lll}
\hline Type of RBC & Associated hematological disease & RBC main morphologies \\
\hline $\begin{array}{l}\text { Sickle cells } \\
\begin{array}{l}\text { Schistocytes and } \\
\text { poikilocytes }\end{array}\end{array}$ & sickle cell trait or disease & sickle, crescents, holly leaf, pecked contours \\
$\begin{array}{l}\text { Elliptocytes } \\
\text { Dacryocytes }\end{array}$ & $\begin{array}{l}\text { sideropenic anemia } \\
\text { hemolytic anemia } \\
\text { anemia in systemic lupus }\end{array}$ & $\begin{array}{l}\text { helmet, fish, ovoids with reduced size } \\
\text { elongated cigar-like with smooth contours } \\
\text { tear drops (round body with an elongated extremity) }\end{array}$ \\
\hline
\end{tabular}

by pyelostomy on the renal pelvis, which caused the direct passage of circulating blood into the excretory urinary system.

For the patient with the elliptocytes in the urine and in the lumen of the renal tubules, there was evidence in the renal biopsy of extravasation of RBC within the interstitium in the context of the acute cellular rejection. Thus, we hypothesize that this caused the passage of RBC into the renal tubules and, hence, in the urine.

For the patient with dacryocytes, the mechanism of hematuria was probably the result of both lupus nephritis (as demonstrated by both the heavy proteinuria and the findings of $15 \%$ dysmorphic erythrocytes, RBC, white blood cells and epithelial casts in the sediment) and the presence of a bladder catheter (as demonstrated by the finding in the sediment of $85 \%$ isomorphic RBC, a moderate leukocyturia and Candida albicans). Therefore, dacryocytes could be due to the bleeding caused by the bladder catheter on the bladder mucosa.

Quite interestingly, the unusual types of RBC found in the urine were always associated with hematological disorders of different types, which were characterized by the presence of $\mathrm{RBC}$ in the blood circulation identical to those found in the urine. This fact raises the question of whether the finding of unusual urinary $\mathrm{RBC}$ as described in this paper may have clinical implications. In this respect, it is important to note that for some of these patients, it was the finding of the unusual $\mathrm{RBC}$ in the urine sediment which initiated further clinical investigation that eventually led to the diagnosis of the hematological disease.

From the morphological standpoint, the RBC described in this paper have peculiar morphologies which make them easily distinguishable from isomorphic and dysmorphic RBC (table 1). In our experience, the only possible misidentification may occur in the presence of urinary $\mathrm{pH} \geq 7.0$ and/or specific gravity $\leq 1.010$, when $\mathrm{RBC}$ can undergo some morphological changes which to some extent may mimic sickle cells or even dacryo- cytes. Another possible misidentification is with isomorphic crenated RBC, which are characterized by the presence of regular spicules protruding form the cell body.

In conclusion, we believe that the rare cases described in this paper further support the evidence that urine sediment examination, when performed by motivated and skilled persons, is still a valuable diagnostic tool for the handling of renal patients [24-27].

\section{Acknowledgements}

The authors thank Dr. Silvana Zeni and Dr. Gabriella Moroni for supplying the clinical information about the patient with dacryocytes in the urine.

\section{Disclosure Statement}

None.

References

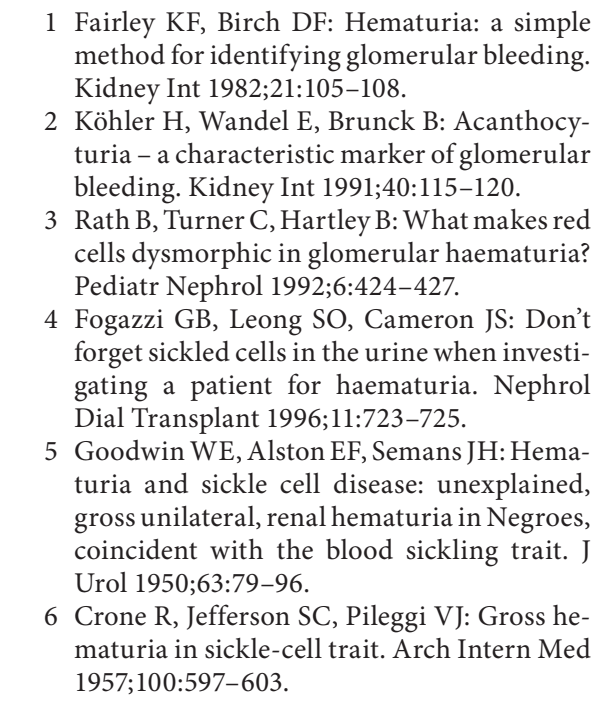

Tesser Poloni/Bosan/Garigali/Fogazzi 
7 Knochel JP: Hematuria in sickle cell trait. The effect of intravenous administration of distilled water, urinary alkalinisation, and diuresis. Arch Intern Med 1969;123:160-165.

$\checkmark 8$ Marynick SP, Ramsey EJ, Knochel JP: The effect of bicarbonate and distilled water on sickle cell trait hematuria and in vitro studies on the interaction of osmolality and $\mathrm{pH}$ on erythrocyte sickling cell trait. J Urol 1977; 118:793-796.

$\checkmark 9$ Savige JA, Birch DF, Fairley KF: Haematuria associated with ureaplasma infection in sickle cell trait. Aust NZ J Med 1982;12:293295.

10 Fogazzi GB: Diagnosing sickle cell disease. Kidney Int 2000;48:463.

-11 Fogazzi GB, Cantu M, Garigali G: Anisocytes and poikilocytes in the urine. Nephrol Dial Transplant 2005;20:840-841.

12 Tichelli A, Gratwohl A, Speck B: Iron deficiency anaemia: diagnosis and therapy. Schweiz Med Wochenschr 1992;12:461-465.

13 Baines AJ: Mechanisms of elliptocytosis: significant spectrin substitutions. Blood 2008; 111:5417.

14 Mohandas N, Gallagher PG: Red cell membrane: past, present, and future. Blood 2008; 112:3939-3948.

- 15 Fogazzi GB, Saglimbeni L, Banfi G, Cantù M, Moroni G, Garigali G, Cesana BM: Urinary sediment features in proliferative and non-proliferative glomerular diseases. J Nephrol 2005;18:703-710.
${ }_{16}$ Kincaid-Smith P, Bennett WM, Dowling JP, Ryan GB: Acute renal failure and tubular necrosis associated with hematuria due to glomerulonephritis. Clin Nephrol 1983;19:206210.

-17 Praga M, Gutierrez-Millet V, Navas JJ, Ruilope LM, Morales JM, Alcazar JM, Bello I, Rodicio JL: Acute worsening of renal function during episodes of macroscopic hematuria in IgA nephropathy. Kidney Int 1985; 28:69-74.

18 Fogazzi GB, Imbasciati E, Moroni G, Scalia A, Mihatsch MJ, Ponticelli C: Reversible acute renal failure from gross haematuria due to glomerulonephritis: not only in $\operatorname{IgA}$ nephropathy and not associated with intratubular obstruction. Nephrol Dial Transplant 1995; 10:624-629.

19 Sheerin NS, Sacks SH, Fogazzi GB: In vitro erythrophagocytosis by renal tubular cells and tubular toxicity by haemoglobin and iron. Nephrol Dial Transplant 1999;14:13911397.

20 Abt AB, Carroll LE, Mohler JH: Thin basement membrane disease and acute renal failure secondary to gross hematuria and tubular necrosis. Am J Kidney Dis 2000;35:533536.
21 Brodsky SV, Satoskar A, Chen J, Nadasdy G, Eagen JW, Hamirani M, Hebert L, Calomeni E, Nadasdy T: Acute kidney injury during warfarin therapy associated with obstructive tubular red blood cell casts: a report of 9 cases. Am J Kidney Dis 2009;54:1121-1126.

-22 Messing EM, Young TB, Hunt VB, Emoto SE, Wehbil JM: The significance of asymptomatic microhematuria in men 50 or more years old: findings of a home screening study using dipsticks. J Urol 1987;137:919-922.

23 Zadeii G, Lohr JW: Renal papillary necrosis in a patient with sickle cell trait. J Am Soc Nephrol 1997;8:1034-1040.

24 Tsai JJ, Yeun JY, Kumar VA, Don BR: Comparison and interpretation of urinalysis performed by a nephrologist versus a hospitalbased clinical laboratory. Am J Kidney Dis 2005;46:820-829.

25 Verdesca S, Brambilla C, Garigali C, Croci MD, Messa P, Fogazzi GB: How a skilful and motivated urinary sediment examination can save the kidneys. Nephrol Dial Transplant 2007;22:1777-1781

26 Györik S, Jandus P, Marone C: Urinalysis: a neglected but easy and inexpensive diagnostic tool. Nephrol Dial Transplant Plus 2009; 2:354-356.

-27 Claure-Del Granado R, Macedo E, Metha RL: Urine microscopy in acute kidney injury: time for a change. Am J Kidney Dis 2011; 57:657-660.

\title{
Editorial Comment
}

\author{
M. El Nahas, Sheffield
}

The review by Poloni, Fogazzi and colleagues reminds nephrologists of the lost art of urine microscopy. They go well beyond glomerular and non-glomerular hematuria as distinguished by the morphology and presence of dysmorphic urinary red blood cells. They describe urinary sickle cells, anisocytes, poikilocytes, dacryocytes and elliptocytes, and illustrate these urinary red blood cells' morphological alterations by the corresponding clinical conditions. The article reflects Tita Fogazzi's passion for urine microscopy. He has turned urine microscopy into a rediscovered science and art. Practicing nephrologists, however, remain divided on the value of urine microscopy. Many hold it in high diagnostic esteem and some even raise it to the level of scientific art. Others, including myself, do not use urine microscopy for diagnostic purposes. I must confess that I have not looked at a single urine sediment in the last 25 years - whether this has affected my diagnostic ability may never be known! 